\title{
AVALIAÇÃO DAS CONDIÇÕES HIGIÊNICO-SANITÁRIAS DE PANIFICADORAS LOCALIZADAS NO MUNICÍPIO DE SANTA MARIA DO PARÁ-PA
}

\section{EVALUATION OF THE HYGIENIC-SANITARY OF BAKERY LOCATED IN THE MUNICIPALITY OF SANTA MARIA DO PARA-PA}

\author{
Saul Lopo Guimarães ${ }^{1}$; Elaine Lopes Figueiredo ${ }^{2}$ \\ ${ }^{1}$ Universidade do Estado do Pará - UEPA - Belém - Brasil saullguimaraes@ hotmail.com \\ ${ }^{2}$ Universidade do Estado do Pará - UEPA - Belém - Brasil lane_figueiredo@yahoo.com.br
}

\begin{abstract}
Resumo
O setor de panificação é um dos que mais cresce em todo o mundo. Devido a esse crescimento promissor, e na busca de atender as novas exigências do mercado consumidor, surge a preocupação com a qualidade higiênico-sanitária das panificadoras. O objetivo do trabalho foi avaliar as condições higiênico-sanitárias de três panificadoras, localizadas no município de Santa Maria do Pará - PA. Utilizou-se a ficha de verificação (check-list), baseada na RDC - $n^{o} 275$ de 21 de outubro de 2002, com 79 itens de verificação, agrupados em quatro blocos: edificação $e$ instalações; equipamentos, móveis e utensílios; manipuladores; e produção e transporte do alimento. Os resultados obtidos com a ficha de verificação mostraram muitas irregularidades nas três panificadoras avaliadas. Nenhuma panificadora foi classificada como Boa (Grupo 1 - 76 a $100 \%$ de itens atendidos). A panificadora A foi a que apresentou as maiores percentagens de adequação higiênico-sanitárias, e a panificadora $B$ apresentou as menores percentagens de adequação, enquadrando todos os itens avaliados como Ruim (Grupo 3 - 0 a $50 \%$ dos itens atendidos). Como nenhuma panificadora apresentou-se em conformidade com a legislação vigente, pode-se afirmar que os alimentos comercializados nestes locais necessitam de uma maior atenção quanto às condições em que são comercializados.
\end{abstract}

Palavras-chave: pão; boas práticas; qualidade.

\section{Introdução}

Nos últimos anos, o segmento de panificação é um dos que mais cresce na economia brasileira, sendo considerado um dos seis maiores segmentos industriais. Segundo dados da Associação Brasileira da Indústria da Alimentação - ABIA, as vendas nas panificadoras crescem cerca de $100 \%$ ao ano, e saltaram de R \$ 3,3 bilhões, em 2006, para R \$ 8 bilhões em 2008. Sua participação no setor industrial de produtos alimentícios é de $36,2 \%$, e na indústria de transformação é de 7 \% (SEBRAE, 2010). 
Apesar da grande importância econômica e de atender diariamente cerca de 40 milhões de pessoas, quase a totalidade das empresas de panificação $(96,3 \%)$ são micro e pequenas empresas, que ainda trabalham de forma artesanal. A incorporação tecnológica no ramo de panificação brasileiro confere grande heterogeneidade aos estabelecimentos. Enquanto poucos utilizam a mais moderna tecnologia na produção e fabricação dos produtos, a maioria faz uso de tecnologia artesanal e sem as mínimas condições higiênico-sanitárias (CAUVAIN e YOUNG, 2002).

A segurança alimentar é considerada um desafio atual. Preconiza alimentos seguros, nutricionalmente adequados e livres de contaminantes de origem química, física e biológica, que podem colocar em risco a saúde dos consumidores (CLEMENTE, 1999; GÓES et al., 2001).

$\mathrm{Na}$ visão atual do consumidor, o conceito de qualidade de um alimento engloba não só as características de sabor, aroma, aparência, textura e padronização, mas também a preocupação em adquirir alimentos que não causem danos à sua saúde (CARDOSO e ARAÚJO, 2001).

De acordo com estudos estatísticos da Organização Mundial de Saúde (OMS), mais de 60 \% dos casos de doenças de origem alimentar decorrem do descuido higiênico-sanitário de manipuladores, das técnicas inadequadas de processamento e da deficiência de higiene da estrutura física, utensílios e equipamentos (OMS, 2010).

$\mathrm{O}$ controle de qualidade em estabelecimentos produtores/industrializadores de alimentos é muito importante. Com base nisso, tem-se como ferramenta indispensável para a obtenção de alimentos higiênicos e seguros, o programa de qualidade Boas Práticas de Fabricação - BPF (SILVA JUNIOR, 2002).

De acordo com a Portaria 368/97, do Ministério da Agricultura e do Abastecimento, as Boas Práticas de Fabricação - BPF são normas e procedimentos exigidos na elaboração de produtos alimentícios para o consumo humano. Referem-se às medidas a serem tomadas pelos estabelecimentos que trabalham com produção de alimentos, para garantia da qualidade sanitária e conformidade dos produtos alimentícios com a legislação vigente (BRASIL, 1997).

A qualidade da matéria-prima, a higienização das instalações, dos equipamentos e dos utensílios, as condições higiênicas do ambiente de trabalho, as técnicas de manipulação dos alimentos, a saúde dos funcionários, o controle da água utilizada, e os cuidados com os vetores transmissíveis de doenças e pragas, são fatores importantes a serem considerados na produção de alimentos de qualidade, devendo, portanto, serem considerados no programa BPF (BRASIL, 2004; SILVA JÚNIOR, 2002).

Associada ao grande crescimento econômico e social do setor de panificadoras, observa-se um grande descaso de seus proprietários e funcionários com a qualidade dos produtos oferecidos. Assim, este trabalho tem como objetivo avaliar as condições higiênico-sanitárias de três 
panificadoras localizadas no município de Santa Maria do Pará-PA, por meio do programa de qualidade Boas Práticas de Fabricação.

\section{Material e Métodos}

\subsection{Caracterização do local}

O estudo foi realizado em três panificadoras comerciais, referenciadas como estabelecimentos A, B e C, localizadas no Município de Santa Maria do Pará - PA, no período de Janeiro à Junho de 2010.

\subsection{Coleta de dados}

A coleta de dados foi iniciada após autorização dos proprietários das panificadoras para a realização do estudo, por meio do método da observação direta e indagações aos funcionários e proprietários. As visitas foram realizadas em dias aleatórios, e no turno da manhã, entre 8:00 e 09:30 horas, horário de maior venda das panificadoras, permitindo avaliação dos procedimentos realmente adotados em cada estabelecimento.

Em cada panificadora, foram realizadas três visitas, a fim de evitar que as observações em um dia atípico pudessem ser decisivas na pontuação, ocasionando erro de análise. Os resultados das avaliações foram expressos pela média dos resultados obtidos.

\subsection{Instrumento de avaliação das condições higiênico-sanitárias}

Para a avaliação das condições higiênico-sanitárias das panificadoras, utilizou-se a Ficha de Verificação (check-list), adaptada do Anexo II, da Resolução de Diretoria Colegiada (RDC) $\mathrm{n}^{\circ} 275$ de 21 de outubro de 2002, do Ministério da Saúde, que dispõe sobre o Regulamento Técnico de Procedimentos Operacionais Padronizados aplicados aos Estabelecimentos Produtores/Industrializadores de Alimentos e a Lista de Verificação das Boas Práticas de Fabricação em Estabelecimentos Produtores/Industrializadores de Alimentos (BRASIL, 2002), sendo adotados os padrões de conformidade de acordo com a RDC n 216 de 15 de setembro de 2004, que dispõe sobre o Regulamento Técnico de Boas Práticas para Serviços de Alimentação (BRASIL, 2004).

A aplicação da ficha de verificação foi realizada em todas as visitas realizadas nas três panificadoras. Nessa ficha, constam 79 itens de verificação, agrupados por assunto em quatro 
blocos: edificação e instalações; equipamentos, móveis e utensílios; manipuladores; e produção e transporte do alimento.

Segundo a $\operatorname{RDC~}{ }^{\circ}{ }^{\circ} 275$, de 21 de outubro de 2002, para se obter o resultado da avaliação das condições higiênico-sanitárias, a partir de um cálculo, são considerados os itens julgados e os itens atendidos. Para os itens com resposta SIM, foi atribuído o valor um (1) e para os itens cuja resposta foi NÃO, foi atribuído o valor zero (0). As respostas SIM foram somadas e em seguida foi calculada a percentagem de adequação, por meio da equação 1 .

$\mathrm{PA}=\underline{\text { itens atendidos } \mathrm{x} 100}$

$$
\text { itens julgados }
$$

\section{Equação 1}

Onde:

PA= Percentagem de adequação

Itens atendidos = número de respostas SIM

Itens julgados = número total de respostas $(\mathrm{SIM}$ e NÃO$)$

A partir desse cálculo, os estabelecimentos foram agrupados de acordo com o percentual dos itens atendidos em

Grupo 1: BOM (76 a $100 \%$ de itens atendidos);

Grupo 2: REGULAR (51 a $75 \%$ dos itens atendidos) e

Grupo 3: RUIM (0 a $50 \%$ dos itens atendidos).

\section{Resultados e Discussão}

A análise dos dados obtidos a partir da ficha de verificação possibilitou constatar que nenhuma dentre as panificadoras avaliadas foi classificada no Grupo 1, considerado o de melhor qualidade higiênico-sanitária e de acordo com o programa de qualidade Boas Práticas de Fabricação $-\mathrm{BPF}$.

As médias dos resultados obtidos com a ficha de verificação (check-list) aplicada nos estabelecimentos estão apresentadas na Tabela 1.

Tabela 1 - Resultados das médias dos escores obtidos com a ficha de verificação aplicada em panificadoras do Município de Santa Maria do Pará - Pará

\begin{tabular}{cccc}
\hline Itens Avaliados & \multicolumn{3}{c}{ Panificadoras } \\
\cline { 2 - 4 } & $\mathrm{A}$ & $\mathrm{B}$ & $\mathrm{C}$ \\
\hline Edificações e Instalações (\%) & 43,75 & 36,25 & 61,90 \\
Equipamentos, móveis e utensílios (\%) & 61,90 & 47,61 & 20,00 \\
Manipuladores (\%) & 40,00 & 33,33 & 50,00 \\
\hline
\end{tabular}


A panificadora A foi a que apresentou as maiores percentagens de adequações higiênicosanitárias, comparada às demais panificadoras. As percentagens dos itens "equipamentos, móveis e utensílios" (61,90 \%) e "produção e transporte de alimentos" (60,60\%), permitem o enquadraramento no Grupo 2: Regular (51 a $75 \%$ dos itens atendidos). A panificadora C apresentou o item "equipamentos, móveis e utensílios” com percentagem (61,90\%) também dentro do Grupo 2. A panificadora B, por sua vez, foi classificada como Ruim, enquadrando todos os itens avaliados no Grupo 3 ( 0 a $50 \%$ dos itens atendidos).

A figura 1 ilustra as médias dos resultados obtidos em cada panificadora avaliada.

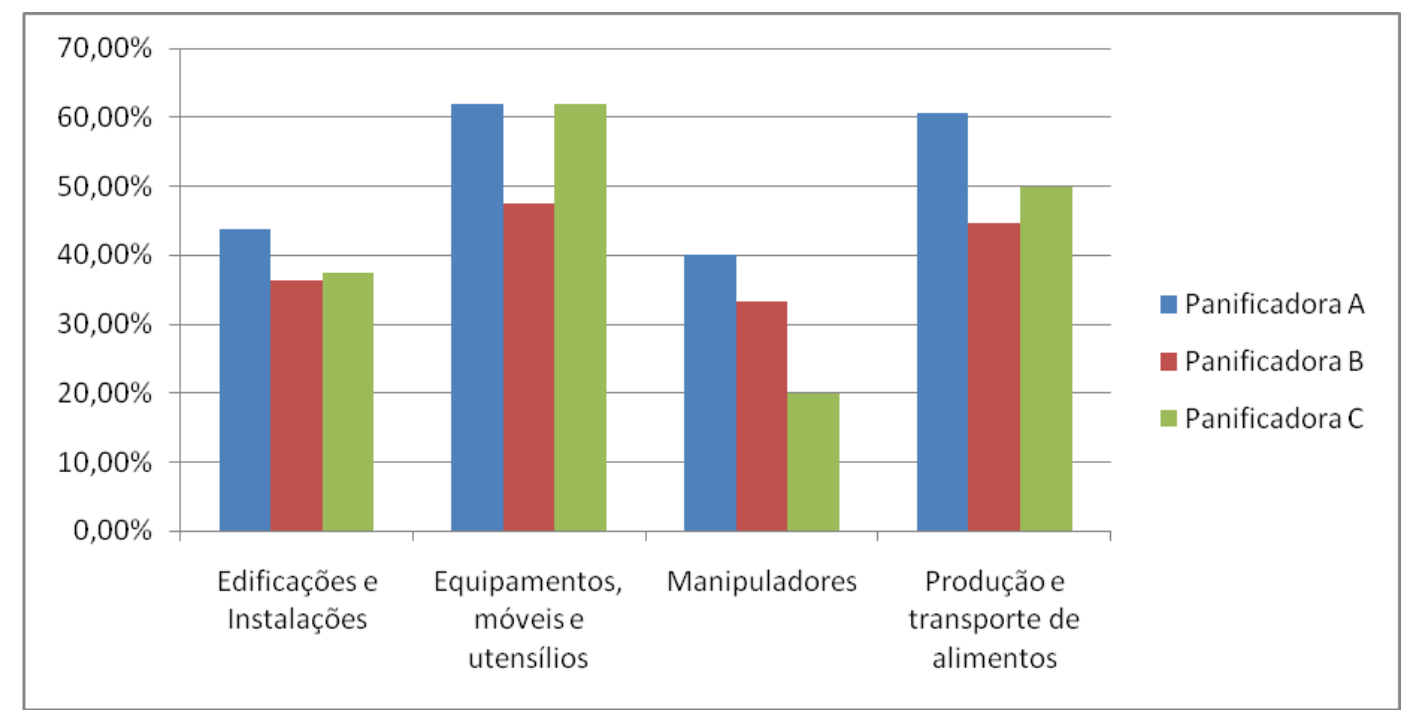

Figura 1 - Médias dos valores obtidos com a ficha de verificação nas panificadoras

Durante avaliação das condições higiênico-sanitárias de panificadoras no Distrito Federal, Cardoso e Araújo (2001) registraram que $5 \%$ dos estabelecimentos foram classificados como Bom, $42 \%$ como Regular, 48 \% como Ruim, e $5 \%$ como Péssimo.

Ao analisar as edificações e instalações das três panificadoras, pode-se verificar que as instalações elétricas e as lâmpadas não se encontravam devidamente protegidas contra acidentes. Portas e janelas não possuíam telas protetoras contra vetores e pragas urbanas. Os tetos das áreas de produção não eram forrados, não impediam o acúmulo de sujeira e apresentavam rachaduras e descascamento, não estando de acordo com a legislação vigente (BRASIL, 2004).

Apenas as paredes da área de produção da Panificadora A encontravam-se pintadas, embora não estivessem em perfeito estado de conservação. As paredes devem ser revestidas de materiais impermeáveis, laváveis, de cores claras, lisas e sem frestas. Os ângulos entre as paredes e o piso e entre as paredes e o teto devem ser abaulados e herméticos para facilitar a limpeza (BRASIL, 1997; BRASIL, 2004). 
Todas as panificadoras encontravam-se em desacordo com a legislação (BRASIL, 2004) no que se refere aos pisos. Nas panificadoras $\mathrm{A}$ e $\mathrm{C}$, os pisos eram de azulejos, porém, não se encontravam em perfeitas condições. Na panificadora B a situação era mais crítica, pois o piso era de cimento bruto, faltando ainda acabamento. De acordo com Brasil (2004) e Aberc (2003) os pisos devem ser de cores claras, lisos, antiderrapantes, impermeáveis, laváveis, de fácil higienização, resistentes a substâncias corrosivas, e que não permita o acúmulo de resíduos. Devem apresentar-se com uma inclinação mínima, em direção aos ralos, suficiente para que a água não estagne.

As três panificadoras também apresentaram inadequações em relação às instalações sanitárias, muito próximas da área de fabricação dos produtos. As paredes dos banheiros encontravam-se sem acabamento e não eram de materiais de fácil higienização. Os vasos sanitários estavam bastante desgastados e as portas não possuíam molas com dispositivo automático, evitando o contato com as mãos. As lixeiras não eram dotadas de dispositivo automático de abertura e não possuíam tampas. Não havia também produtos apropriados para a higienização correta das mãos.

O abastecimento de água nos estabelecimentos é da rede pública, com encanações protegidas, em bom estado de conservação, sem rachaduras e vazamentos, diminuindo assim riscos de contaminação da água. Somente a panificadora A possuía reservatório próprio, com limpeza periódica mensal, realizada por um funcionário do próprio estabelecimento. Este reservatório encontrava-se em bom estado de conservação, sem vazamentos e rachaduras, sendo a sanitização realizada com a utilização de compostos clorados, um dentre os mais recomendados (ANDRADE e MACÊDO, 1996; RAMOS, 2001).

As panificadoras não possuíam uma área específica para a coleta e armazenamento do lixo. As lixeiras das partes internas dos estabelecimentos também estavam sem ou dispositivos automáticos de abertura. De acordo com Santos (1999) deve-se destinar uma área somente para o armazenamento do lixo. Este deve ser colocado em estrados altos, para evitar a presença de animais, roedores e pragas, e sempre com tampas bem ajustadas.

Durante as visitas, foi observada a presença de vetores na área de produção. Nenhuma dentre as panificadoras visitadas apresentou registros sobre o controle integrado de pragas. Os proprietários afirmaram fazer uso de métodos químicos, executados por serviços terceirizados, e desconheciam o tipo de substância utilizada. Também desconheciam os riscos que estas substâncias podem trazer para a integridade dos alimentos e para os seres humanos, podendo comprometer a saúde de seus funcionários e clientes.

O item "equipamentos, móveis e utensílios" foi o que apresentou as maiores percentagens de adequação às Boas Práticas de Fabricação. Os equipamentos utilizados nos estabelecimentos, apesar do muito tempo de uso, encontravam-se em perfeito funcionamento, sem colocar em risco a qualidade do produto. Os equipamentos e os utensílios utilizados no processo de elaboração dos 
pães eram higienizados logo após seu uso, eram armazenados em armários bem conservados, limpos e protegidos de insetos e pragas, após a higienização. Somente a panificadora B apresentou algumas irregularidades com relação à higienização correta dos utensílios.

Valejo et al. (2003) quando vistoriaram 52 serviços de alimentação, na cidade de Presidente Prudente-SP, constataram que os maiores problemas foram em relação à má conservação de utensílios e equipamentos. Segundo Hobbs e Roberts (1998) os equipamentos e utensílios podem ser responsáveis por contaminações cruzadas, devendo assim ser de fácil limpeza e desinfecção, facilmente desmontáveis e montáveis. O risco de contaminação aumentará se um mesmo equipamento e/ou utensílio for utilizado para atividades e alimentos diferentes. Os utensílios devem ser armazenados em local apropriado, de forma organizada e protegidos contra a contaminação.

O item que obteve as menores percentagens de adequações foi o de "manipuladores". Nas três panificadoras verificou-se que os manipuladores não tinham o hábito de usar uniformes completos e equipamentos de proteção individual - EPI's, estando fora dos padrões estabelecidos pela legislação (BRASIL, 2004). Além disso, verificou-se também que algumas manipuladoras utilizavam adornos, como relógio, pulseira e brincos, durante o trabalho. A lavagem correta e periódica das mãos também não era realizada pelos funcionários.

A avaliação do perfil dos funcionários revelou que $75 \%$ deles desconheciam ou negligenciavam a adoção correta de prática de higiene, indicando a importância da supervisão e a capacitação periódica dos manipuladores em higiene alimentar.

De acordo com Góes et al. (2001), a educação e o treinamento periódico dos manipuladores de alimentos, em todas as fases do processamento, são importantes para a manutenção da qualidade higiênico-sanitária dos alimentos, visto que a maioria das toxinfecções alimentares está relacionada com a contaminação do alimento pelo manipulador.

Quanto ao item "produção e transporte dos alimentos", observou-se que após a elaboração dos produtos de panificação, os mesmos eram deixados à temperatura ambiente até sua venda, o que poderia comprometer sua qualidade higiênico-sanitária. Apesar dos produtos terem sido submetidos a altas temperaturas no momento de sua produção, a exposição prolongada em temperatura ambiente e sem proteções adequadas contra insetos, pode causar a contaminação microbiológica desses alimentos.

\section{Conclusão}

A partir da análise dos resultados obtidos com a lista de verificação, pode-se concluir que as três panificadoras avaliadas apresentaram elevado grau de não conformidades, não possuindo 
condições higiênico-sanitárias satisfatórias, em desacordo com o programa de qualidade Boas Práticas de Fabricação - BPF.

A panificadora A foi a que apresentou as maiores percentagens de atendimento dos itens, enquanto a panificadora, os valores mais baixos, enquadrando todos os itens avaliados no Grupo 3 (0 a $50 \%$ dos itens atendidos).

O item "equipamentos, móveis e utensílios" foi o que apresentou maior percentual de itens em adequação com as Boas Práticas de Fabricação, e o item com as menores percentagens de adequações foi o de "manipuladores".

Para que o setor de produção e comercialização de alimentos possa sempre oferecer aos consumidores, alimentos de qualidade higiênico-sanitária, este trabalho sugere que os órgãos fiscalizadores intensifiquem os treinamentos, a partir de cursos e palestras, para que os manipuladores de alimentos possam ter conhecimento dos sistemas de controle de qualidade. É importante também que os estabelecimentos possuam responsáveis técnicos, os quais possam implementar o Programa de Boas Práticas de Fabricação - BPF.

\begin{abstract}
The bakery sector is one of the fastest growing worldwide. Due to this promising growth, and in seeking to meet the new demands of the consumer market, there is concern about the sanitary quality of bakeries. The objective of this study was to evaluate the hygienic and sanitary conditions of three bakeries, located in Santa Maria of Pará - PA. We used the plug check (check-list) based in the DRC - no. 275, of October 21, 2002, which had 79 check items, grouped into four blocks: building and facilities, equipment, furniture and fixtures; handlers; and production and transportation of food. The results with the plug check showed many irregularities in the three bakeries evaluated. No bread was classified as Good (Group 1 - 76-100\% of items met). The bakery was the one with the highest percentages of the adequacy of sanitary-hygienic, bakery and B had the lowest percentages of adequacy, fitting all the items rated as Poor (Group $3-00-50 \%$ of items met). Because no baking is presented in accordance with current legislation, we can say that the food sold in these places need more attention on the conditions in which they are marketed.
\end{abstract}

Key-words: bread, good practice, quality

\title{
Referências
}

ABERC. Manual ABERC de Práticas de Elaboração e Serviço de Refeições para Coletividades. 8 ed., 2003.

ANDRADE, N.J.; MACÊDO, J.A.B. Higienização na Indústria de Alimentos. São Paulo: Varela, 1996.

BRASIL. Ministério da Saúde. Resolução RDC n. 216, de 15 de setembro de 2004. Regulamento Técnico de Boas Práticas para Serviços de Alimentação.

BRASIL. Ministério da Saúde. Resolução RDC n. 275, de 21 de outubro de 2002. Regulamento Técnico de Procedimentos Operacionais Padronizados aplicados aos Estabelecimentos Produtores/Industrializadores de Alimentos.

BRASIL. Ministério da Agricultura, Pecuária e Abastecimento. Portaria no 368, de 04 de setembro de 1997. Regulamento Técnico sobre as Condições Higiênico-Sanitárias e de Boas Práticas de Elaboração para Estabelecimentos Elaboradores/Industrializadores de Alimentos. Brasília: Ministério da Agricultura, 1997. 
CARDOSO, L.; ARAÚJO, W. M. C. Perfil higiênico-sanitário das panificadoras do Distrito Federal. Higiene Alimentar, v. 15, n. 83, p. 32-43, 2001.

CAUVAIN , S.P.; YOUNG, L.S. Fabricacion de pan. Zagaroza.: Acribia, 2002.

CLEMENTE, E.S. Controle higiênico-sanitário em supermercados. In: CONGRESSO NACIONAL DE HIGIENISTAS DE ALIMENTOS, Foz do Iguaçu. Anais... São Paulo: Higiene Alimentar, v. 13, n. 61, 1999.

GÓES, J. A.W.; FORTUNATO, D. M. N.; VEloso, I. S.; SANTOS J. M. Capacitação dos manipuladores de alimentos e a qualidade da alimentação servida. Higiene Alimentar, v. 15, n. 82. p. 20-22, mar., 2001.

HOBBS, B. C.; ROBERTS, D. Toxinfecções e controle higiênico-sanitário de alimentos. São Paulo: Varela, 1998.

OMS. Organização Mundial de Saúde. Foodborne disease, disponível em <hhtp:www.who.int>. Acesso em: 3 jun. 2010.

RAMOS, A. M. F. Manual para Funcionários na Área de Alimentação e Treinamento para copeiras hospitalares. 1 ed. São Paulo: Varela, 2001.

SANTOS, S. S. G. F. Treinando manipuladores de alimentos. São Paulo: Varela, 1999.

SEBRAE. Novo convênio vai apoiar setor de panificação no país, disponível em:<http://www.planodenegocios.com.br/www/index.php/informcao/noticias/2345-

Novo\%20conv\%C3\%AAnio\%20vai\%20apoiar\%20setor\%20de\%20panifica\%C3\%A7\%C3\%A3o\%20no\%20Pa\%C3\% ADs>. Acesso em 05 mai. 2010.

SILVA JUNIOR, E.A. Manual de Controle Higiênico-Sanitário em Alimentos. 4. ed. São Paulo: Varela, 2002.

VALEJO, F. A. M.; ANDRÉS, C. R.; MANTOVAN, F. B.; RISTER, G. P.; SANTOS, G. D.; ANDRADE, F. F. Vigilância sanitária: avaliação e controle de qualidade dos alimentos. Higiene Alimentar, v. 17, n. 106, p. 16-21, 2003.

\section{Dados completos do autor para correspondência:}

Nome completo: Elaine Lopes Figueiredo

Filiação institucional: Universidade do Estado do Pará - UEPA

Departamento: Tecnologia de Alimentos

Função ou cargo ocupado: Professor Assistente I

Titulação: Mestre

Endereço completo para correspondência (bairro, cidade, estado, país e CEP): Av. Tavares Bastos, $\mathrm{n}^{0}$ 961. Bairro: Marambaia. Belém, Pará, Brasil. CEP: 66.615.005

Telefones para contato: (91) 8109-2612.

e-mail: lane_figueiredo@yahoo.com.br 